\title{
Identity-Related Issues in Meme Communication Francisco Yus
}

\begin{abstract}
Internet memes are an example of the trend of replicability and spread of discourses through the Net within today's participatory culture. On paper, memes are instances of humorous discourse that abound on the internet, are replicated or altered, and then transmitted to other users. However, in this paper the focus is not on its humorous side, but on how every single stage of meme communication entails a greater or lesser impact on the user's self-concept, self-awareness and overall identity. The paper addresses five stages of meme communication and possible ways in which these stages influence the user's identity.
\end{abstract}

Keywords: memes, online identity, cyberpragmatics, image macros

\section{Introduction}

This paper addresses how meme communication impacts the user's identity, to a greater or lesser extent, in all of its stages ranging from the initial decoding of the meme by the addressee user to his/her final decision upon whether to spread the meme to other users or not, and upon whether to alter the meme or not once the decision to spread the meme has been taken. For such account, it is necessary to broaden the role of meme-generated humor beyond the basic generation of humorous effects, and we also need to broaden the sources of user's identity shaping and user's self-awareness beyond the typical intentional acts of communication, with a propositional shape, and within the user's awareness. The paper will show that memes, specifically the image macro memes analyzed, generate offsets of identity related feelings and emotions beyond the initial purpose of replicated humor.

\section{Memes and internet memes}

The term meme is commonly associated with the idea of cultural unit proposed by Dawkins (1976) as having the capacity of infecting people's minds with a kind of duplicating replicability, imitation being key to the survival of this cultural item. Further definitions of the term include Naughton's (2012) “an infectious idea which replicates itself," Blackmore's (1999) “whatever it is that is passed on by imitation" and Knobel \& Lankshear's (2007: 201) "popular term for describing 'catchy' and widely propagated ideas or phenomena." Therefore, in this initial conceptualization, memes are the analogous to the biological concept of gene, in the sense that they are self-replicating and communicated from person to person. Memes are units of information, ideas or mental representations, cultural instructions that are not only selfreplicating but also contagious (Taecharungroj \& Nueangjamnong 2014: 152).

For this initial concept of meme, Dawkins (1976) proposed three main characteristics: (a) fidelity (the meme can be readily copied and transmitted from person to person without significant alteration in shape or format), (b) fecundity (a high rate at which the information is copied and spread), and (c) longevity (the capacity of the meme for survival in a chained spreading process).

From this initial idea of meme, replicating pieces of information that spread through the Net through user-to-user(s) communication have been labeled similarly: internet memes. This is not surprising, since these memes do share some properties initially ascribed to memes in general. Among the definitions, we can cite (a) groups of digital items (such as images or videos) that 
share common characteristics, are created with awareness of each other, and are distributed online by multiple participants (Shifman 2014). (b) Any artifact that appears on the Internet and produces countless derivatives by being imitated, remixed, and rapidly diffused by countless participants in technologically mediated communication (Dynel 2016: 662). And (c) a relatively complex, multi-layered, and intertextual combination of (moving) image and text that is disseminated by the active agency of internet users, becoming popular among them (Laineste \& Voolaid 2016: 27).

The qualities of internet memes led some researchers to equate them to virals. This is understandable, since virals spread across digital media in unchanged form (Dynel 2016: 662) and they are forwarded from one person to others, within and between multiple weakly linked personal networks, resulting in a rapid increase in the number of people who are exposed to the message (Shifman 2014: 55). However, there is only a partial overlapping between the qualities of memes and virals: the fact that both of them can be intentionally transmitted in an unaltered format. However, virals typically tend to spread beyond the user's intention rather than intentionally. For example, a user may write an online review of a hotel which, for some unexpected reason, goes viral beyond the user's initial intention. This is not possible in memes, which are intentionally created and transferred. Besides, memes are often altered by the free software available on the Net, whereas virals tend to spread unaltered.

Crucially, a distinctive feature of internet memes is that they are invariably ascribed to a "family" and part of their effective processing entails this initial family ascription (Nissenbaum \& Shifman 2017: 484, Segev et al. 2015: 418). In this paper, I will focus on a particular family of memes: the image macro memes, made up of a line of text on top of the meme, another one at the bottom and one picture in the middle, with a number of interesting text-image combinations with pragmatic implications.

\section{Broadening the role of humor and of identity-shaping strategies and effects}

If we want to get a full extent of the impact that meme communication exerts on users, we need to broaden both the scope of humor and humorous effects, on the one hand, and of the sources of identity shaping and self-awareness, on the other. Both "broadenings" are commented upon below.

Firstly, memes are typically regarded as humorous discourses, although they may also be very critical, in a similar way to cartoons in the press (Yoon 2016: 97). Besides, they tend to be referred to as "jokes" even though they rather fit the label of "instance of humor" (Dynel 2016: 668). When users are sent a meme, one of the default expectations is that they be humorous in some way (Miltner 2014). This is coherent with the fact that users tend to share more positive than negative stories. They like to transfer surprising, interesting and useful content which provides feedback on the user's identity in a positive way via replies and likes, content that makes other users feel good while stressing the entertaining and upbeat attributes of the sender users, and this default interest in information transmission explains the centrality of humor as the most forwarded category in viral spread of information (Shifman 2014: 66-67).

Besides, some image macro memes such as the ones analyzed in this paper are clearly humorous since they exhibit the typical incongruity-resolution pattern of humorous discourses (cf. Yus 1997, 2016a, in press), even though variations are found which are inherent to this medium. An example is Dynel (2016), who analyzes memes such as the ones depicted in Figure 1. These memes do exhibit an incongruity resolution pattern, since the initial accessible interpretation of slip into and runs into has to be invalidated as the subsequent stretch of 
discourse is processed (an incongruity turns up). The user then has to backtrack and re-interpret these verbs differently (so as to obtain a resolution). Clearly, these memes exhibit similar humorgenerating inferential stages to typical incongruity-resolution-centered jokes.

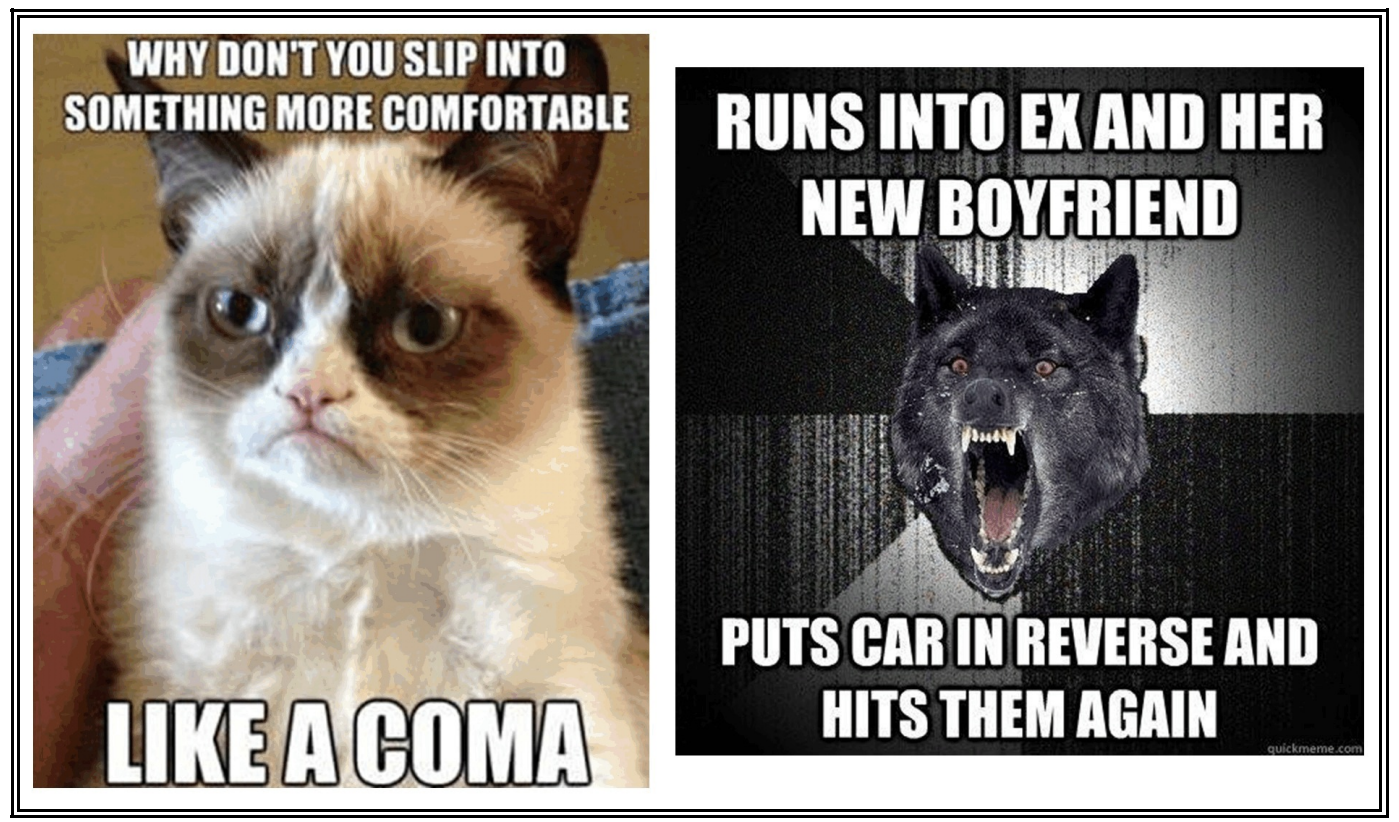

Figure 1.

However, the eventual relevance of humorous discourses may not only rely on the derivation of humorous effects, but also (and sometimes mainly) on the derivation of certain non-humorous non-propositional effects by the interlocutors. These aspects may lie beyond the act of communication and its initial intentionality, but nevertheless affect the eventual (ir)relevance of the overall act of online communication (Yus forthcoming a), which is also applicable to meme communication and its effects on identity. In previous research, the term non-intended non-propositional effect was added to the general proposition-based cyberpragmatic analysis (Yus 2016b, 2017). It refers to (non-propositional) feelings, emotions, impressions, etc. which are not overtly intended by the sender user, but are generated from the act of communication, and add (positively or negatively) to the cognitive effects derived from utterance interpretation (propositional content). In Yus (forthcoming a) some humor-related nonpropositional effects are listed, including (a) enhanced awareness of mutuality existing between interlocutors; (b) feelings of enhanced group membership, group specificity and group solidarity; and (c) more fine-grained ability to extract humorous effects. These may also be triggered by the act of meme communication beyond its initial discursive interpretation.

Something similar occurs with the effects of memes on users' identities. Initially, it can be stated that identity is not fixed, but a discursive-performative construct that takes form in specific social and cultural contexts. People go through multiple identities on a daily basis and they shift identities (and their related language uses) depending on the social situations they encounter (Shophocleous \& Themistocleus 2014). In Yus (2011), a picture of the user as a node was proposed, in which the user (and the user's physical body) is a stable anchorage where a number of physical and virtual interactions (correlated with virtual and physical identities) intersect, often with the user being unable to distinguish them (interactions and/or identities) in terms of strength or impact on sociability, self-concept or community bonding. Of course, the user can 
intentionally upload a propositional discourse with an awareness of being expecting feedback as "likes" or replies. This is typical of what in Yus (2014) was called interactivity triggers, texts or visual discourses uploaded on social networking sites such as Facebook with the underlying intention to get as many comments and replies as possible. The user may also use a certain type of discourse with full awareness of the communicative barriers that its use entails and underlines. In Yus (forthcoming c), an example is provided of the use of letters and numbers (instead of Arabic characters) among the Tunisian youth, a sort of hieroglyphic that is only comprehensible to them, and not to others such as some adults with whom they do not want to share the information from their posts, thus emphasising their group membership and feelings of community bonding. An example from a Tunisian Facebook dialogue is quoted in (1), together with its translation -and comments- in (2):

(1) User 1: hhhhh rit kifeh normalemnt User 4 hya eli ta3ti elmahba.

User 2: $\quad$ s7i7 w lezemha t5arej el Fatra 3la chahriyetha lol ken mazelt ma 5arajtech ya User 4 a3ti el amir 7ata $50 \mathrm{~d}$ sada9a tadfa3ou al bala2

User 3: 7ata enaaaaaaaaaaa :)

User 4: A User 2 walah 5arejet fatra ...yezi 9alu 5o dinars ....men antom hahaha ....mesbeh wena na3ti metfakerni ken 3 am hamadi yaatih esaha ...naarefkom ghayrlin hhhh

(2) User 1: hhhhh you see, normally User 4 has to offer the mahba [tradition in which money is offered as a present for Eid al-Fitr, celebrated after Ramadan; normally offered to children].

User 2: it's true and she also has to give the fatra for having a job [an amount of money stipulated by imams and given to the poor], we propose User 4 to offer Amir 50 dinars as mahba and fatra, so that bad omens will be suppressed.

User 3: to me too [she has to offer the mahba].

User 4: User 2, I swear I already did the fatra... and also the 50 dinars... you are naughty... I haven't stopped offering the mahba all day... the only person who did not forget to give me the mahba is uncle Hamadi... I am sure you're jealous.

Again, analyzing identity in terms of intentional discourses with a propositional format and within the user's full awareness would not suffice to explain the role that meme communication plays in the user's self-concept or self-awareness (Yus 2016c). Here, the term non-intended non-propositional effect comes to the rescue, covering feelings and emotions generated by virtual discourses and interactions beyond their initial intentions and interpretations and which may even lie beyond the user's full awareness. As du Preez \& Lombard (2014: 260) correctly describe, identity is mainly constructed through interpersonal interactions, and the social and physical environment. While a user may try to portray an ideal construction of the self while online, with full awareness of the underlying identity-related intentionality, in most instances this performance is not viewed as a conscious act and it partly remains subconscious, depending on the situation (environment and audience). In other words, although the performance of a specific aspect of identity may be deliberate, it is not entirely a conscious act. My point in previous research is that it may also be non-propositional, based on feelings and emotions devoid of a propositional format.

In Yus (forthcoming b), some identity-related non-propositional effects are listed, including (a) feelings of connectedness; social awareness, feelings of being part of the interactions and friendships; (b) feelings of reduced loneliness; (c) feelings of being noticed by others, by the user's community, feedback; (d) feeling more willing for self-disclosure; (e) generation of 
bridging and bonding social capital; and (f) feeling of well-being through emotional display. These may also be generated by memes beyond their initial interpretation as instances of textualvisual discourses.

\section{User's identity throughout meme interpretation and transference}

The main aim of this paper is to show that all stages of meme communication may have an impact, to a greater or lesser extent, on the user's identity, self-concept or self-awareness. In the next Sections, an account of these stages will be provided, starting with meme decoding, and followed by the subsequent stages: inferring, sharing, strengthening and spreading.

\subsection{Decoding}

At this initial stage, we should underline the user's awareness of his/her command at the initial recognition of the discourse as an instance of a meme together with its intended basic function of replicability. As Ballesteros Doncel (2016: 26) correctly stresses, the grammar of memes cannot be dissociated from the digital capabilities of those who create and re-create them. This initial identification may impact the user and make him/her aware of being part of a certain group of those who manage and are fully updated on the kind of specific information that is currently exchanged on the Net.

Besides, the ability to trace the "family" (or genre) to which memes belong makes the user aware of his/her competence at this meme identification, and signals which further actions may or may not be taken (du Preez \& Lombard 2014: 256). In Yus (2007) a similar proposal is made for the identification of areas and sections of the blog interface.

Furthermore, the identification of the discursive qualities of the meme signals appropriateness and, ultimately, group membership. This is also the case when coding the meme with the easy-to-use software available on the internet for both creating and altering memes. This is related to the general importance of genre identification in internet communication, not only for the user's self-awareness, but also for the appropriate management of interactions. As Miltner (2014) summarizes, genre is considered to be an essential element of online communication since the effective use of online documents depends on an underlying (and expected) ability to recognize its nature, structure, and purpose (which somehow signals group membership, even if within broad limits). Furthermore, genre dictates not only the way communications are structured, but the way they are received, in the sense that genres are both socially constructed and constructing (i.e. produce effects on community bonding). Genres are essential to understand how to participate in the collective actions of a community within the trend of participatory culture. Indeed, whether textual or social, genres are important framing devices, especially as generic conventions set up expectations. An example is the LOLCat genre. Miltner (ibid.) uses this family of memes to illustrate how the form and structure of the LOLCat are distinct, the proper execution of the generic conventions being essential to its appeal. Participants repeatedly refer to font, text placement, image subject, and animal characterization as integral to the enjoyment of a LOLCat. In other words, adherence to specific design elements is considered paramount to LOLCats enjoyment, and also reinforces collective bonding and awareness of group membership.

\subsection{Inferring}


When users forward a meme, they expect that it is going to raise expectations of relevance and prospects that its processing is going to be worth the mental effort required for obtaining an appropriate interpretation. Needless to say, meme inference is context-dependent is two main ways:

Firstly, inferring memes is context-dependent because inference takes different directions depending on where the meme is located (as a Facebook entry, as a WhatsApp message to a group...) and on the comments by other users, which get "attached" as an indissoluble part of its meaning. Therefore the user's identity is shaped differently depending on these discursive attachments and placements.

Du Preez \& Lombard (2014: 259) point in the same direction when they state that memes particularly add to a person's online identity when interpreted in conjunction with the rest of the discourse, specifically the Facebook profile, but they may lead to unwanted misunderstandings if placed in a de-contextualized scenario. These authors exemplify this "contextual constraint" with a meme posted on Facebook, a variation of the 'Keep calm and carry on' meme, but in this case the yellow poster depicts a block of butter with the caption 'Keep calm and add butter.' What is the intended interpretation of this meme? Well, if interpreted in isolation, it could merely point to the user's love of butter, but if read in conjunction with another post, inference will take a different path. Du Preez \& Lombard (ibid.) list possibilities such as the user possibly being a chef or simply passionate about cooking; or the possibility of turning out insulting if related to another user's weight problems. This is illustrative of the multiplicity of interpretations for a meme, which are dependent on the environment in which they are located, with the discursive context (e.g. Facebook) providing useful clues that may lead the addressee in the right inferential direction.

Secondly, inferring memes is context-dependent in the determination of the relationship between text and image yielding explicatures and implicatures (both verbal and visual). In the case of image macro memes, there is a default order of interpretation if the meme is to be successfully understood (Dynel 2016: 678). Thus, in image macro memes, as in other visualverbal humorous discourses, the text and the picture are consecutively processed, and the interpretative results of the two are ultimately brought together, even if sometimes the image will initially catch the user's attention and then the text will be incorporated to this initial interpretation of the visual area of the meme.

In previous research (e.g. Yus 2009, 2016a), some space was devoted to determining whether we can apply the term explicature, explicit interpretations of verbal utterances, to visual stimuli. The pragmatic implications of combining text and image in one single piece of discourse were also analyzed. One of the claims was that, in the same way as we have explicit interpretations (explicatures) and implicit or implicated interpretations (implicatures) of verbal utterances, visual content can also lead to visual explicatures and visual implicatures (see Forceville 2014, Forceville \& Clark 2014, and Wharton 2009 for discussion). In the same way that we set inferential resources in motion in order to access a suitable context that aids in obtaining the most relevant explicit and/or implicated interpretation of a verbal utterance, when faced with a verbal-visual discourse such as a meme, the user also has to engage in inferential hypotheses concerning the role that images play in the comprehension of the meme, that is, the user has to infer whether the picture has a purely denotative quality, in which case it would be a visual explicature, or it has a non-coded and wholly inferential connotative quality that can only be obtained from the combination of the image and contextual information. In this case, we would be dealing with a visual implicature.

Specifically, in the processing of memes, the triggers for the various stages of inference are 
distributed not strictly linearly as in joke texts, but are spatially arranged, even across the modes of picture and text. Thus, the inferential processes may be more easily teased apart operationally and, consequently, empirically into various constellations of stages and their successions than it is possible in verbal humor (Hempelmann \& Samson 2008: 626). Therefore, upon finding a meme, the user will have to engage in the following inferential strategies (Yus 2016a):

Strategy 1. Decoding and inferentially enriching the verbal content of the meme in order to obtain the explicit interpretation of the text or explicature.

Strategy 2. Deriving verbal implicatures from verbal content, if these are necessary to reach a relevant interpretation of the verbal content of the meme.

Strategy 3. Decoding and inferentially enriching the image(s) depicted to yield so-called visual explicatures. Indeed, the mere perception and identification of the images of the meme is not enough, and is followed by an enrichment that contextualizes these pictures in the specific scenario of the meme.

Strategy 4. Deriving implicatures or implications from the visual content of the meme, if these are necessary to reach an adequate interpretation of the meme as a whole.

Strategy 5. Inferring possible combinations of text and image to yield interpretations (typically implicated ones or verbal-visual implicatures) that are only possible from the combination of these sources of information (text and image) and not from either of them taken separately (Tsakona 2009: 1172). Very often, the information from the images will lead to an inferential backtracking after the accompanying text has been processed, in the light of the information provided by visual content. On other occasions, the text will force a new reading of the image, resulting in either a new visual explicature or leading to the derivation of a previously unforeseeable visual implicature.

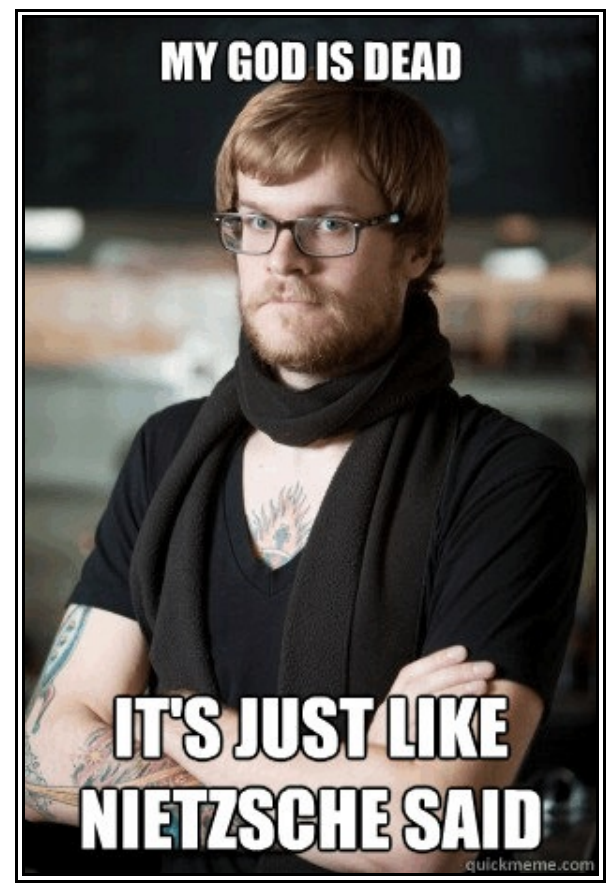

Figure 2.

In terms of identity, it can be stated that managing to get the right interpretation of the meme (not only from the partial meanings of text and image, but also because sometimes the meme is related to very specific news or events), together with being aware of this interpretive capability 
may impact the user's self-awareness. This is particularly noticeable in the case of memes which demand specific background knowledge as part of the context needed to get the point of the meme. The users, upon realizing that they were able to get the intended interpretation, are aware of their status regarding a collectivity of users. An example is found in Milner (2012: 93) concerning an instance of meme (Figure 2), which demands a lot of background knowledge in order to get the right interpretation, information which is, of course, expected and taken for granted by the sender of the meme, and also acknowledged by the addressee user, who feels an offset of identity-enhancing effects. Among other inferential operations, for the correct interpretation of this particular meme in Figure 2, the addressee user has to infer the referent of "my God" (Steve Jobs) and adjust the coded concept for "God" metaphorically; access the background knowledge of the type of meme depicted (Hipster Barista) and access background knowledge of the fact that hipsters love Apple products, together with some background knowledge on Nietzsche and in which circumstances that phrase was produced.

The importance of expected mutuality plus offset of identity-enhancing effects have already been studied concerning stand-up performances, where the comedian's speech on shared cultural information triggers a "joy of mutual manifestness," using the relevance-theoretic term (more on this below). Also for irony, mutuality of information is expected, to the extent that this information also reveals how close interlocutors are. As commented upon in Yus (2016b: 224), many instances of irony are only meant to stress mutually manifest assumptions. Close friends will use irony to get a vivid picture of portions of mutuality that would otherwise be difficult to assess, to bring the interlocutor closer, to obtain greater intimacy (see also Yus 2016d).

It comes as no surprise that intertextuality plays a major role in this management of information leading to a proper interpretation of the meme and subsequent impacts on identity. Laineste \& Voolaid (2016: 28) comment on how through the act of sharing cultural texts such as memes, internet users resort to and generate "social memory through becoming engaged in an active dialogue with previous cultural texts and with potential audiences." Intertextuality, then, is a central feature in social bonding, since the reference(s) enacted through intertextuality may shape the meaning depending on the availability (and mutual awareness) of the reference frames of the audience as a delimited virtual group or community.

This expectation of background knowledge is also applicable to the process of meme creation and subsequent "acting on it" by the community of users. For example, Meikle (2016: 55) comments on how "an internet meme is a shared representation of online interaction. The rules and structures of each instantly recognizable meme are a representation of the communication practices and the particular online space in which it was developed."

\subsection{Sharing}

To forward a meme (i.e. to share it with friends, communities or acquaintances) is to expect that the addressee is going to find the meme worth processing, probably through an offset of humorous effects and feelings of group membership that compensate for the mental effort involved in its interpretation. Let us not forget that sharing and participatory culture are key terms of today's conceptualization of the Web 2.0 (Shifman 2014: 19, Gofton 2017: 28, Wiggins \& Bowers 2015: 1891), so meme communication does not merely have to do with passing information along to other users, but mainly with a sharing social phenomenon. However, it is also an individual phenomenon. Every time a meme is shared, the addressee user engages in its processing through pragmatic inference (explicit/implicated interpretations), but this inference is biased by the addressee user's personal cognitive environment (his/her beliefs, ideas, 
background knowledge, moral attitudes, etc.).

Besides, this processing of the textual-visual content of the meme also generates a personal array of (positive/negative) non-propositional effects, mainly humorous effects, but also identity-related effects such as (1) feeling of group membership, (2) feeling of connectivity with others, (3) feeling of peer validation and acknowledgment, (4) feeling of command of today's discourses exchanged on the Net, etc. In this sense, there are different levels of impact on identity depending on whether the "addressee user" feels that he/she is part of a "mass circulation" of the meme, or feels that the "sender user" has deliberately chosen him/her as selective recipient of the meme.

At this stage of meme communication, the important issue is the decision of whether to forward the meme unaltered or with alterations. The "audience validation" of the altered meme makes the user "stand out" from the crowd, to feel unique and valued by the members of the community. But even with unaltered memes, the group is both identified by the choice of who the meme is transferred to and by the acknowledgment by the group of the acceptability of the transferring action (audience validation). An example is the altered memes in Figure 3 arising from the initial top-left meme.

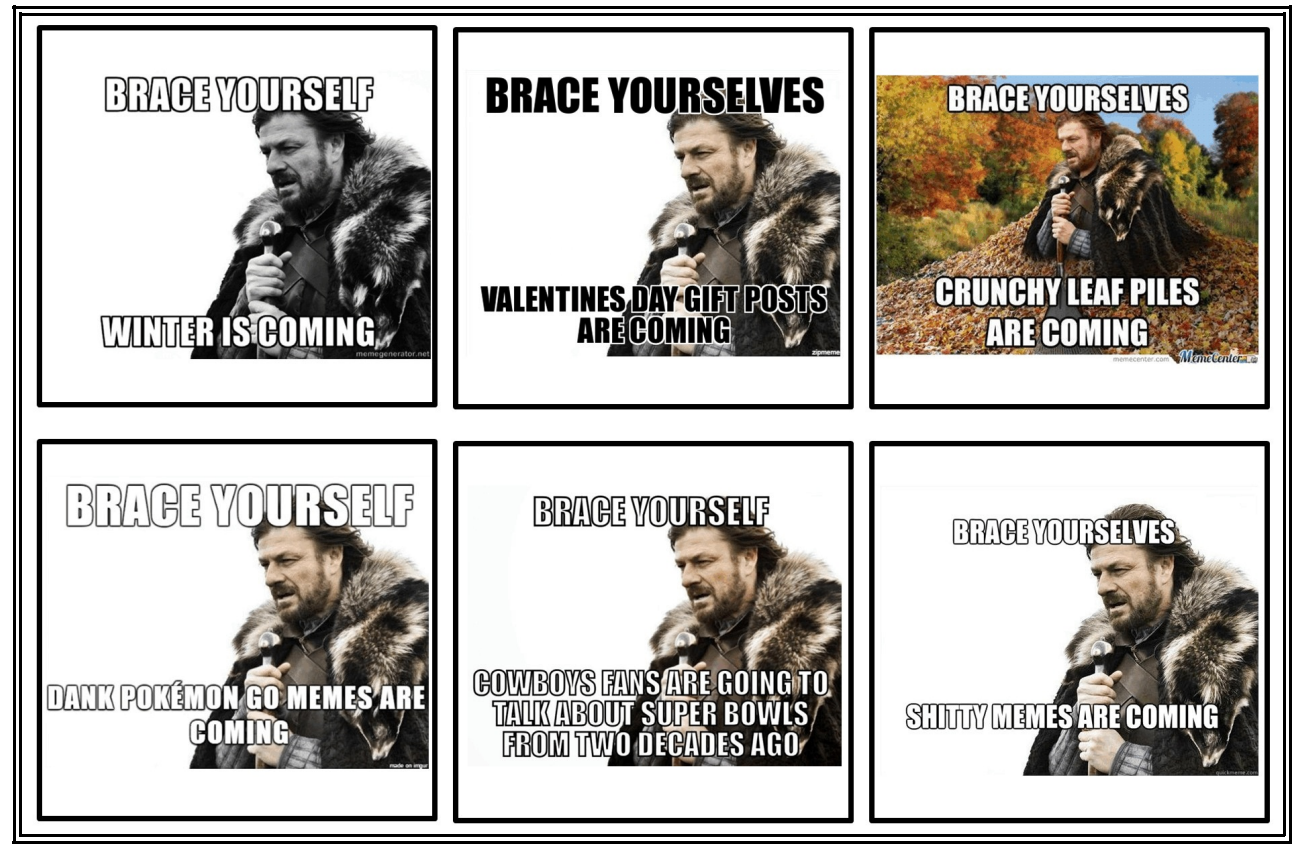

Figure 3.

As Meikle (2016: 50-51) asserts, communication through social media is an unfinished process of circulation and connection, of relationships and associations. Each new sharing strategy thus opens up different kinds of connectivity and different possibilities for meaning, and each makes possible different possibilities of content circulation to other people. "Each connection both establishes new relations between individuals and makes visible previously invisible connections. Internet memes are forms of easily remixed texts and images that are intrinsic to this social media environment."

\subsection{Strengthening}


Memes demand shared knowledge within a community, and their processing generates barriers of discursive specificity, and hence a strengthening of in-group membership and attributes of the collectivity.

The association between cultural capital and Internet memes relates both to memes' unique creation processes and to the social dynamics surrounding them. "Meme literacy" influences users' status in online communities and indicates membership (Nissenbaum \& Shifman 2017: 486). Similarly, memes have been noted to show participants' discerning use of intertextual media, mixing and matching popular culture references to demonstrate affective affinities with others (Kanai 2016).

In this sense, it seems that identity through group norm fitting, group validation and in-group enhancement, as enacted by meme communication (i.e. social identity and community bonding) are more essential for users than identity through being unique at creating something beyond the norms imposed by the group (Konstantineas \& Vlachos 2012). Postmes \& Baym (2005: 224) agree with this priority of the social when they underline the fact that personal identities "are simultaneously properties of the group itself because they could not exist without some degree of consensus from the group." Similarly, Milner (2012: 42) states that "memes are often produced on sites where social collectives come together and define themselves at least loosely as a group. (...) Mediated cultural participation means dispersed social collectives can more thoroughly engage with others who share similar social identities." In this sense, an interesting approach is that of networked individualism, standing somewhere in-between the joy of being individual and the joy of feeling the approval of the group. Shifman (2014: 33-34) summarizes this idea as follows: we witness an era of accelerated individualization, and hence people are expected to fashion a unique identity and image and by doing so actively construct their own unique selves. But at the same time, individuals participate enthusiastically in the shaping of social networks, demonstrating an enduring human longing for community bonding. User-generated versions of a meme may serve both purposes: on the one hand, users who exhibit their individuality show they are digitally literate, unique, and creative. But at the same time, what they upload as individual often relates to common, widely shared rules or formulas. As a result, users simultaneously indicate and construct their individuality and their affiliation with the larger community.

In any case, in my opinion for an offset of social identity, it is crucial for meme communication to obtain group validation (Guadagno et al. 2013:2313), more so than standing out by avoiding established norms of meme communication, even though some process of negotiation invariably takes place. In Gal et al.'s (2015: 1700) words, the memetic practice is not merely an expression of existing social-cultural norms, it is also a social tool for negotiating them. The relationship between memes and norms is thus twofold: memes both reflect norms and constitute a central practice in their formation.

This idea also applies to the social validation of the semiotic qualities of the meme and the environment within which it is located. Du Preez \& Lombard (2014: 257) are right in pointing out that only those memes that are suited to their 'socio-cultural environment' are likely to spread, which entails that memes are selected by users who belong to a specific virtual social environment with a purpose of complimenting the environment in which they are posted. This means that memes make a semiotic contribution to the semiotic environment in which they are located.

Additionally, an offset of feelings of collective identity may be generated from the appropriate use of language within the group of meme users. A clear example is LOLCats (Miltner 2014). Lolspeak was rigid in its rules and prone to collective awareness. Its appeal was 
that this language made no sense outside the community of users, thus creating vivid enhancement of in-group solidarity through successful production and comprehension of that language. Examples of lolspeak utterances include the one provided in (3) (Miltner ibid.):

(3) Lolspeak: Ohai! I wud like tu $b$ in deh focus groop, if it am alrite wif $u$

English: Hi! I would like to be in the focus group, if that is alright with you

Clearly, as Milter (ibid.) correctly points out, Lolspeak was seen as a source of enjoyment, but also worked as an indicator of who was truly committed to the community. Speaking "perfect Lol" was seen as a great accomplishment that only few could master. This was illustrated in discussions of the level of virtuosity demonstrated by the head of the community. Those who are unable (or unwilling) to master the rules of Lolspeak are seen as less invested, even if they are active contributors to the community in other ways.

\subsection{Spreading}

An inherent quality of memes is that they replicate and spread across virtual groups and communities, much like cultural items get propagated across populations.

When we talk about culture, we refer to relatively stable representations which can be found in the minds of most of the members of a community. In the context of meme communication, these shared representations also concern how this type of discourse should be created, transferred and which possible alterations to the meme are allowed (audience validation), as was commented upon above. But even if memes spread unaltered, it would be a mistake to assume that all the addressees of the meme will interpret the meme in the very same way and that they will be equally willing to spread the meme to their friends, acquaintances or communities (see below).

As was commented upon at the beginning of this paper, memes are also transmitters of information disseminated throughout a population of friends and communities of users. In previous research, when applying this idea of cultural transmission during stand-up comedy performances (Yus 2002, 2004, 2005, 2016a), two main models of cultural dissemination were contrasted: Dawkins' (1976) gene-like model (memetics) and Sperber's $(1984,1996)$ virus-like view (epidemiology of representations).

(A) Memetics. There is no doubt that cultural representations are transmitted and spread through a population and that communication is one basic method of transmission. According to the memetic stance, cultural representations duplicate in the process of transmission, as can be deduced from these quotes: "I argue that more complex human cognitive processes, such as language, reading, scientific research and so on, all build in some way on the ability to imitate, and therefore all these processes are, or can be, memetic. When we are clear about the nature of imitation, it is obvious what does and does not count as a meme. I suggest that we stick to defining the meme as that which is passed on by imitation" (Blackmore 1998). "The whole point of memes is to see them as information being copied in an evolutionary process" (Blackmore 2001).

(B) The epidemiology of representations. Supported especially by Sperber $(1984,1996)$, the epidemiological stance favors a different picture in which imitation is viewed as a limiting case, rather than the norm. Cultural representations do maintain a certain degree of stability when transmitted from person to person, but communication inevitably involves an interaction between the new input and the person's individual background knowledge, opinions and beliefs (the 
users' personal cognitive environment), and the resulting effect is only partly predictable. Within this approach, the mutuality of information (made available through communication) plays a crucial role in the formation, stability, and transmission of certain cultural information among the population. The audience can, in turn, transform these mental representations into publicly transmittable ones later on (e.g. memes), thus adding to a chained propagation and, eventually, to this virus-like (epidemiological) view of cultural spread.

Hence, the main aim of an epidemiology of representations is to explain how the individual processing of information is communicated across minds and favor the transmission of representations (Sperber 1996: 50). This is clearly applicable to meme communication, in which individual mechanisms (creation and/or modification of a meme with available software) and inter-individual mechanisms (decision to spread the meme across platforms and communities) interact in the eventual mutuality of representations across users. A causal chain is created in which mental representations communicated with a meme are turned into public representations (the same meme or an altered meme transferred), which modify the mental representations of the addressee users (e.g. they are highly manifest to these users, using a relevance-theoretic terminology). These addressee users may aid in a subsequent chained spread of more of less similar versions of the memes.

However, meme communication does not seem to thoroughly fit either memetics or epidemiology. Some memes spread unaltered, thus fitting the memetic gene-like view of cultural transmission, but those memes that are altered (very frequent ones due to easy-to-use software available on the internet) do not seem to fit this view. These alterations seem to fit more the epidemiological view, for which duplication is a limiting case, and transformations between mental representations (information) and public stimuli (the meme) are regarded to be the norm. But again, some memes spread unaltered and this seems to be at odds with this view of duplication as infrequent.

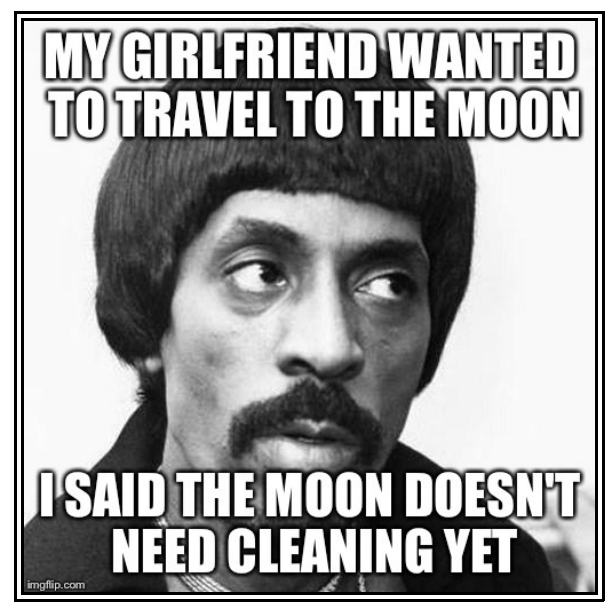

Figure 4.

In any case, it would be a mistake to assume that all the users who infer the same unaltered meme will come up with the same interpretation plus non-propositional effects, and that these users will be equally willing to forward the meme to their friends or communities. In fact, the epidemiological view still applies here, since the meme is processed against a very personal background of each addressee user, which affects both interpretation and related nonpropositional effects, and this influences future actions by the user concerning the spread of the 
meme. Take, for instance, the sexist meme depicted in Figure 4. Upon receiving this meme, different interactions with individual users will be produced depending on the users' own beliefs and ideas about women's role compared to men's (overlapping, overall matching, utterly different, etc.). Furthermore, different interactions with individual users will generate a number of non-propositional effects: Some users will be amused; others will be disgusted. Some will feel part of the group; others will wish they were not part of the group, etc. And these unique interactions with specific users will determine both the eventual interpretation obtained (propositional and non-propositional) and the user's willingness to engage in the chained propagation of the meme.

\section{Concluding remarks}

In this paper an account of identity-related issues has been proposed for all the stages of meme communication: decoding, inferring, sharing, strengthening and spreading. For such account, I have proposed a broadening of the role of humor beyond the generation of humorous effects, and also a broadening of the role of identity-related acts of communication. Beyond the typical intentional act in which propositional content is communicated to an addressee who is fully aware of the identity-related intention (e.g. a post of a new photo on Facebook or a text functioning as "interactivity trigger"), in this paper more possibilities have been proposed by including unintentional generation of non-propositional effects (feelings, emotions, impressions, etc.), which play a role in the users' identity shaping and self-awareness. As a result, it can be stated that all the stages of meme communication, one way or another, impact the user's identity, which is essential in today's society, where physical areas for the shaping of identity are frequently exchanged for virtual scenarios which are the locus of many interactions and the place where information sharing and spreading mainly take place nowadays.

\section{References}

Ballesteros Doncel, Esmeralda. 2016. "Circulación de memes en WhatsApp: Ambivalencias del humor desde la perspectiva de género." Revista de Metodología de Ciencias Sociales 35: 21-45.

Blackmore, Susan. 1998. "Imitation and the definition of a meme." Journal of Memetics 2(2).

Blackmore, Susan. 1999. The Meme Machine. Oxford: Oxford University Press.

Blackmore, Susan. 2001. "Evolution and memes: The human brain as a selective imitation device." Cybernetics and Systems 32(1): 225-255.

Dawkins, Richard. 1976. The Selfish Gene. Oxford: Oxford University Press.

du Preez, Amanda, and Elanie Lombard. 2014. "The role of memes in the construction of Facebook personae" Communicatio 40(3): 253-270.

Dynel, Marta. 2016. "I has seen image macros!' Advice animal memes as visual-verbal jokes." International Journal of Communication 10: 660-688.

Forceville, Charles. 2014. "Relevance Theory as model for analyzing visual and multimodal communication." In Visual Communication, ed. by D. Machin, 51-70. Berlin: Mouton de Gruyter.

Forceville, Charles, and Billy Clark. 2014. "Can pictures have explicatures?" Linguagem em (Dis) curso (special issue on relevance theory) 14(3): 451-472.

Gal, Noam, Limor Shifman, and Zohar Kampf. 2015. “It Gets Better': Internet memes and the construction of collective identity." New Media \& Society 18(8): 1698-1714.

Gofton, Pete. 2017. "Music, memes and meaning: A semiotic analysis." Musicology Research 2: 27-46.

Guadagno, Rosanna E., Daniel M. Rempala, Shannon Murphy, and Bradley M. Okdie. 2013. "What makes a video go viral? An analysis of emotional contagion and Internet memes." Computers in Human Behavior 29: 2312-2319. 
Hempelmann, Christian F., and Andrea C. Samson. 2008. "Cartoons: Drawn jokes?” In The Primer of Humor Research, ed. by Victor Raskin, 609-640. Berlin: Mouton de Gruyter.

Kanai, Akane. 2016. "Sociality and classification: Reading gender, race, and class in a humorous meme." Social Media + Society October-December: 1-12.

Knobel, Michele, and Colin Lankshear. 2007. "Online memes, affinities, and cultural production." In $A$ New Literacies Sampler, ed. by Michele Knobel, and Colin Lankshear,199-227. Berlin: Peter Lang.

Konstantineas, Charalambos, and George Vlachos. 2012. "Internet Memes. Humor in late modernity and encroachment upon the mainstream." Inter-disciplinary.net.

Laineste, Liisi and Piret Voolaid. 2016. "Laughing across borders: Intertextuality of internet memes." European Journal of Humour Research 4(4): 26-49.

Meikle, Graham. 2016. Social Media. Communication, Sharing and Visibility. Abingdon: Routledge.

Milner, Ryan M. 2012. The World Made Meme: Discourse and Identity in Participatory Media. PhD Thesis. University of Kansas.

Miltner, Kate M. 2014. "“There's no place for lulz on LOLCats': The role of genre, gender, and group identity in the interpretation and enjoyment of an Internet meme." First Monday 19(4).

Naughton, John. 2012. From Gutenberg to Zuckerberg: What You Really Need to Know about the Internet, London: Quercus.

Nissenbaum, Asaf and Limor Shifman. 2017. "Internet memes as contested cultural capital: The case of 4chan's /b/ board." New Media \& Society 19(4): 483-501.

Postmes,Tom, and Nancy Baym. 2005. "Intergroup dimensions of the internet." In Intergroup Communication: Multiple Perspectives, ed. by Jake Harwood, and Howard Giles, 213-238. New York: Peter Lang.

Segev, Elad, Asaf Nissenbaum, Nathan Stolero, and Limor Shifman. 2015. "Families and networks of Internet memes: The relationship between cohesiveness, uniqueness, and quiddity concreteness." Journal of Computer-Mediated Communication 20: 417-433.

Shifman, Limor .2014. Memes in Digital Culture. Cambridge, MA: The MIT Press.

Shophocleous, Andry, and Christiana Themistocleus. 2014. "Projecting social and discursive identities through code-switching on Facebook: The case of Greek Cypriots.” Language@Internet 11.

Sperber, Dan. 1984. “Anthropology and psychology: Towards an epidemiology of representations." Man 20: 73-89.

Sperber, Dan. 1996. Explaining Culture. A Naturalistic Approach. Oxford: Blackwell.

Taecharungroj, Viriya, and Pitchganut Nueangjamnong. 2014. "The effect of humour on virality: The study of Internet memes on social media." Paper presented at 7th International Forum on Public Relations and Advertising Media Impacts on Culture and Social Communication. Bangkok, August.

Tsakona, Villy. 2009. "Language and image interaction in cartoons: Towards a multimodal theory of humor." Journal of Pragmatics 41: 1171-1188.

Wharton, Tim. 2009. Pragmatics and Non-Verbal Communication. Cambridge: Cambridge University Press.

Wiggins, Bradley E., and G. Bret Bowers. 2015. "Memes as genre: A structurational analysis of the memescape." New Media \& Society 17(11): 1886-1906.

Yoon, InJeon. 2016. "Why is it not Just a joke? Analysis of Internet memes associated with racism and hidden ideology of colorblindness." Journal of Cultural Research in Art Education 33: 92-123.

Yus, Francisco. 1997. "La teoría de la relevancia y la estrategia humorística de la incongruenciaresolución." Pragmalingüística 3-4: 497-508.

Yus, Francisco. 2002. "Stand-up comedy and cultural spread: The case of sex roles." Babel A.F.I.A.L., special issue on humour studies, p. 245-292.

Yus, Francisco. 2004. "Pragmatics of humorous strategies in El club de la comedia. In Current Trends in the Pragmatics of Spanish, ed.by Rosina Márquez-Reiter, and María E. Placencia, 320-344. Amsterdam: John Benjamins.

Yus, Francisco. 2005. “Dave Allen's stand-up monologues: An epidemiological approach.” In Thistles. A homage to Brian Hughes. Volume 2: Essays in Memoriam, ed. by José Mateo, and Francisco Yus, 
317-344. Alicante: University of Alicante, Department of English Studies.

Yus, Francisco. 2007. "Weblogs: Web pages in search of a genre?" In The Texture of Internet. Netlinguistics in Progress, ed. by. Santiago Posteguillo, María José Esteve and M. Lluïsa GeaValor, 118-142. Cambridge: Cambridge Scholars Press.

Yus, Francisco. 2009. "Visual metaphor versus verbal metaphor: A unified account." In Multimodal Metaphor, ed. by Charles Forceville and Eduardio Uriós-Aparisi, 145-172. Berlin: Mouton de Gruyter.

Yus, Francisco. 2011. Cyberpragmatics. Internet-Mediated Communication in Context. Amsterdam: John Benjamins.

Yus, Francisco. 2014. "El discurso de las identidades en línea: El caso de Facebook." Discurso \& Sociedad 8(3): 398-426.

Yus, Francisco. 2016a. Humour and Relevance. Amsterdam: John Benjamins.

Yus, Francisco. 2016b. "Towards a cyberpragmatics of mobile instant messaging." In Yearbook of Corpus Linguistics and Pragmatics 2016: Global Implications for Culture and Society in the Networked Age, ed. by Jesús Romero-Trillo, 7-26. Berlin: Springer.

Yus, Francisco. 2016c. "Discourse, contextualization and identity shaping. The case of social networking sites and virtual worlds." In New tools, New Approaches. Technology implementation in Higher Education for Second Language Teaching and Translation Studies, ed. by María Luisa Carrió-Pastor, 71-88. Berlin: Mouton de Gruyter.

Yus, Francisco. 2016d. "Propositional attitude, affective attitude and irony comprehension." Pragmatics \& Cognition 23(1): 92-116.

Yus, Francisco. 2017. "Contextual constraints and non-propositional effects in WhatsApp communication." Journal of Pragmatics 114: 66-86.

Yus, Francisco. in press. "Incongruity-resolution cases in jokes." Lingua.

Yus, Francisco. forthcoming a. "Positive non-humorous effects of humor on the Internet." In The Dynamics of Interactional Humor. Creating and Negotiating Humor in Everyday Encounters, ed. by Villy Tsakona and Jan Chovanec. Amsterdam: John Benjamins.

Yus, Francisco. forthcoming b. "Relevance from and beyond propositions. The case of online identity." In Relevance and Irrelevance: Theories, Factors and Challenges, ed. by Hishashi Nasu and Jan Strassheim. Berlin: Mouton de Gruyter.

Yus, Francisco. forthcoming c. "The interface between pragmatics and Internet-mediated communication: Applications, extensions and adjustments." In Pragmatics and its Interfaces, ed. by Cornelia Ilie and Neil Norrick. Amsterdam: John Benjamins. 